hats off, to pay their respects to Don, as minister from a friendly power. The Doctor kept himself close back in the carriage until directly opposite the coffee-house, the gentlemen all bowing and scraping, when he pops out his head. 'Good morning, gentlemen, good morning; I hope you are all well; thank you in the name of His Majesty, King George,' and drove off, laughing heartily at having again joked with the Philadelphia Whigs." At the time when the mob carted Dr. John Kearsley, Jr., the son of the architect of Christ Church, and another violent Tory, through the streets, Chovet only escaped the same fate by hiding in the stable of Mr. Marshall. As a rule, however, Dr. Chovet, so far as his politics were concerned, seems to have been regarded as an amusing and eccentric old gentleman whose idiosyncrasies were harmless. He certainly never endured the gross indignities which befell so many of his fellow Tories.

Dr. Chovet brought from England a collection of wax models, and dried and injected anatomic preparations, and in the winter season of $1774-75$ he delivered a series of anatomic lectures illustrated by them, of which he made the following announcement:

$$
\text { AT THE ANATOMICAL MUSEUM }
$$

in Videl's Alley, Second Street, on Wednesday, the Seventh of December at six in the evening

\section{DR. CHOVET}

will begin his course of Anatomical and Physiological Lectures, in which the sereral parts of the human body will be demonstrated, with their mechanism and actions, together with the doctrines of life, health and the several effects resulting from the actions of the parte; on his curious collection of Anatomical wax-works, and other natural preparations; to be continued the whole winter until the course is completed. As this course cannot be attended with the disagreeable sight or smell of recent disease and putrid carcases, which often disgust even the students in Physick, as well as the curious, otherwise inclined to this useful and sublime part of natura philosophy, it is hoped this undertaking will meet with suitable encouragement.

Tickets to be had for the whole courseat Dr. Chovet's house in Second Street, Philadelphia.

On Nov. 24, 1783, Dr. John Foulke received permission from the board of managers of the Pennsylvania Hospital to use one of the upper rooms of the building known as the "elabratory" of the hospital for the purpose of giving lectures on "Chirurgical and Physical Subjects during the season." He was not only, according to Watson, reckoned "the best surgeon of his day," but ulso "the next best skater" in the city; "skating 'High Dutch,' and being able to cut his own name at one flourish, constituted the Doctor's fame as a skater." In 1784 he opened "An Anatomical Hall" with a "determination to put the character of a Philadelphia anatomist upon a higher footing than it had ever before been," also asserting, "that in his pursuit he was determined to observe every attention to decency, solemnity and punctuality." The charge was $\$ 12$ a course. He continued giving these courses of lectures until his death, in 1796, and they seem to have been very largely attended.

There were several other lecture courses given in Philadelphia toward the end of the last century, which are worthy of note, indicating what an active center the city was in the development of medical education on this continent. Dr. John Hannum Gibbon, who was a Pennsylvanian by birth, graduated from the University of Edinburgh, in the medical department, in 1786 ; returned to this country and married a Miss Heysham of Philadelphia, after which he settled in the latter city, on Arch Street. In 1789 and for some years afterward he lectured on the "Theory and Practice of Medicine." He died at the early age of 36 years, on Oct. 5,1795 . Norris also mentions the lectures on midwifery, delivered by Dr. Benjamin Duffield, from 1793 until his death in 1799. Dr. Duffield also lectured on "Diseases of Hospitals and Jails," and "The American Practice of Physic." According to Norris, Drs. Church and James continued his obstetric lectures after his death. The same authority speaks of a course of lectures by Dr. Price of London, delivered in Philadelphia toward the close of the century, on "The Theory and Practice of Physick," and "Midwifery and the Diseases of Women and Children," and of the course on obstetrics given by Dr. Dewees in 1797.

\section{PELVIC DISEASE.}

IS IT A CAUSE OF NERVOUS AND MENTAL AFFECTIONS?

Presented to the Section on Obstetrics and Diseases of Women at the Forty-ninth Annual Meeting of the American Medical Association, held at Denver. Colo., June 7-10, 1898. BY FREDERICK PETERSON, M.D.

President of Board of Managers of Craig Colony for Epileptics; Chief of Clinic, Nervous Department, College of Physicians and Surgeons; Clinical Professor of Insanity in the Woman's Medical College. NEW YORK CrTY,

It was in the sixteenth century that Montaigne, a friend of physicians, though a hater of their art, wrote, that it was safer to follow the example of the ancient Egyptians and employ specialists for each particular organ of the body than to trust one's self to the general practitioner. "As we have doublet- and breechesmakers, distinct trades, to cloath us, and are so much better fitted, being that each of them meddles only with his own business, and has less to trouble his head withal, than a taylor that undertakes all; and as in matter of diet, great persons, for their better convenience, and to the end they may be better served, have cooks of distinct offices, some for soops and pottages, and others for roasting, which one cook that should undertake the whole service, could not so well perform, so must we be treated in our cures." If that were good advice in Montaigne's day, how much more valuable must it be to-day when the bounds of scientific medicine have expanded far beyond the vision and comprehension of any one man!

No single mind can grasp and practically apply the vast store of human knowledge accumulated in the domain of the healing art during the past century. And, yet, upon the whole it seems to me that the well-rounded general practitioner has a wider field of usefulness to society than the ordinary specialist of the present day, and for this reason, that the majority of specialists carry their specialism too far. The tendency is for each to consider his narrow spot the center around which the whole human microcosm revolves. It is very much as though one should say that the sole object of human life is manufacture of a skeleton. For is not the skeleton the most enduring part of the body? Does it not last ages after the individual has disappeared? What are the muscles for if not to move the skeleton? For what purpose are the viscera, if not to nourish the muscles; and the nervous system, if not to regulate nutrition and govern the muscles in their manipulation of that supreme apparatus, the skeleton?

The specialist, to be superior to the general practi- 
tioner, should first of all equal him in a broad understanding of the principles of general medicine, and upon such foundation rear the superstructure of his specialty. He must regard man as a biologic unit in which every organ has its due place and proportion in the harmonious unity. While his own sphere of activity will nuturally engross the most of his attention, the specialist should not apotheosize the eye, the nose, the uterus, or any single viscus and make it the divinity to which all the other organs must kneel. It is a species of intellectual myopia which has led some specialists, for instance, to attempt to include a large number of neuroses and psychoses, such as neurasthenia, hysteria, chorea, epilepsy, mania, melancholia, etc, among the disorders dependent upon changes in any viscus which chances to loom up overwhelmingly in their intellectual horizon. It would be vastly amusing, were it not all too often tragic, to observe the alacrity with which some of them seize upon one unfortunate organ as the sole offender in the animal economy. Woe to the individual afflicted with some nervous disorder who should by any sorry chance pass through the hands of a series of such specialists! She would be dissected piecemeal. Her eye muscles would naturally be slashed for a year or two by the ophthalmologist, who recognizes in muscular insufficiencies the origin of chorea, epilepsy, insanity and the like. The long-suffering turbinated bones would be the next to go. Then the rectum would be the site of surgical procedures, after which the clitoris, ovaries and uterus would be the object of attack. The remaining viscera being of minor consequence, the patient may then be safely turned over to the stomach specialist, or referred back to the family physician, or seek perpetual refuge in some hospital, sanitarium or asylum. Is this a picture drawn from the imagination, or is it not rather a faithful sketch of a not infrequent spectacle? Naturally, there is no one present who will, after my preliminary sentences, misunderstand me as berating all specialists. You, as well as I, feel that the specialist who is broad-minded and honest enough to look upon man as a biologic unit, will never fall into the egregious errors just portrayed.

I have been interested, since I was honored with the invitation to discuss this question, to examine five of the best works on gynecology which have been issued within the last three years, with reference to their treatment of the relations of nervous and mental disorders to pelvic disease. Three of the books had nothing to say upon the subject. Two of them discussed the subject from quite different standpoints. One of the writers could be classified among the narrow specialists to whom I have just referred. In one paragraph he states that the disorders of the nervous system resulting from disturbed menstruation "partake of the nature of chorea, hysteria, epilepsy, hystero-epilepsy, migraine and neurasthenia. These, together with nymphomania and other varieties of perverted sexual appetite, onanism and insanity, will be especially referred to." I can not reconcile such statements with others in the same chapter upon the causes of disordered menstruation, among which nervous and mental diseases are alleged to play an important etiologic rôle. An example of the author's point of view is his somewhat sweeping classification of insanity, He says: "For our present purposes all cases [of insanity] may be classified as follows: 1, those which are purely central, from cere. bral causes; 2, those which are the result of female sexual diseases from reflex causes." What will the ophthalmologist, rhinologist and rectal specialist say to this? Where are now the exponents of the new theory of auto-intoxication?

It is a pleasure to turn from this author to the chapter on the nervous system in relation to pelvic diseases, in the little book on "Diseases of Women," by J. C. Webster (1898), in which the broad position for which I contend is assumed by the writer. The tenor of his dissertation may be inferred from one quotation, as follows: "Too strong a protest can not be urged against the centralization of attention on the local pelvic conditions without regard to wider physical and psychic relationships." I could wish, to be sure, that the author had been guided throughout his brief chapter by the wise dictum just quoted, but it is difficult for any man to free himself wholly from the traditions of his art and the contagion of his environment. The chapter, however, should be an excellent guide for generations of gynecologists yet to $\operatorname{com} \theta$, and I should feel safe in entrusting a nervous patient to a specialist in diseases of women who holds such views. Old Carl von Braun of Vienna, with whom I studied gynecology in my younger days, was wont to speak of the uterus as the Pandora box of woman's woes, a designation comprehensive enough to embody the opinion of all too many of his successors. Were sex determined anatomically by the pelvic organs alone, there might be some excuse for giving them that prominence in pathology for which certain gynecologists, especially those afflicted with the manie operatoire, contend. But femininity does not reside solely in the pelvic organs; it pervades the entire organism of woman, her bones, muscles, breasts, viscera and nervous system, and even her mind. The disorders of her pelvic organs have no more to do with her nervous and mental diseases than lesions elsewhere in her body: indeed, they have less to do with her psychoses and neuroses than most of her other organs, for, as in the male sex, the chief causes of their neuropsychoses are to be sought in intrinsic disorders of the nervous system itself, or in perverted nutrition of the nervous system dependent upon affections of the gastro-intestinal tract, kidneys, liver, lungs, heart, etc., and upon pathologic blood states.

It is true that puberty, adolescence, the puerperium, menstruation and the menopause are often closely related to the outbreak or the exacerbation of many nervous and mental disorders, but the pelvic organs themselves play but a small rôle in these physiologic commotions. They have to do with the whole organism of woman. These commotions influence the entire biologic unit. They disturb for a time, the intricate and harmonious adjustment of that central nervous system which serves to correlate and govern the thousands of delicate functions performed within the body, so that during such periods of unstable equilibrium, the chief factors in the etiology of the neuroses and psychoses find the biologic unit more vulnerable to attack. I do not deny that pelvic diseases in women, attended by exhausting pain, may give rise to neurasthenic and hysteric states, but the influence of exhausting pain in these organs is no greater than similar exhausting pain elsewhere in the body. Nor do I deny that disorders of the female organs which affect the nutrition of the nervous system, such as excessive hemorrhage, or suppurative processes, may be important factors in inducing func- 
tional neuroses and even insanity, though disordered blood states brought about by pelvic disease are very infrequent as compared with disordered blood states dependent upon disease elsewhere. These are the main concessions, such as they are, that $I$ should be willing to make in the argument with the gynecologist. There is no evidence whatever to support the opinion that insanity was ever due to a mere reflex influence from pelvic disease. In insanity the two great etiologic factors are hereditary instability and some physical or moral stress directly affecting the nervous system. There has never been brought forward any evidence whatever to show that either epilepsy or chore can be induced by disease of the female organs. I take the stand, therefore, that the field of the gynecologists in the domain of nervous diseases is comparatively restricted and unimportant, and $I$, in common with the best men of their own specialty, raise $\mathrm{my}$ voice in strong protest against the still prevailing tendency to enlarge the field of operative gynecology by unjustifiable and unscientific surgical interference in cases of nervous and mental disease. It is better to do too little than too much. It is better to err on the side of science than to give the patient the so.called "benefit of the doubt," which should rather be called the affliction of the doubt. Let the gynecologist by all means treat any serious disease of the pelvic organs which may be present in any case of nervous or mental disorder just as he would a similar affection in an otherwise sound and sane woman, but let him not sacrifice upon the altars of strange gods those who trust to his knowledge, skill and broad judgment. The rellex neuroses and psychoses are will o' the wisps that iead one into obscure places, into a maze, and then vanish, leaving him astray, bewildered, remote from any familiar landmark.

4 W. 50th Street.

\section{EPIDEMIC CEREBROSPINAL MENINGITIS} BY W. J. CLASS, M.D.

MEDICAL INSPECTOR CHICAGO HEALTH DEPARTMENT. CHICAGO.

INTRODUCTION.

The objects which led to the investigation of which this report is the outcome were: 1 , to ascertain whether true epidemic cerebrospinal meningitis existed in the city of Chicago, and 2, to trace if possible its origin and the avenues by which it spread. In regard to the first of these objects, it was soon discovered that there was a greater prevalence of the disease than was generally supposed, and enough data were collected, which we hope are of sufficient interest to the general practitioner, to excuse the writer for encroaching on those particulars of the disease which, strictly speaking, do not perhaps belong to the territory of the sanitarian. Chicago has for a number of years fortunately escaped the ravages of a disease which has been in a constantly increasing number of instances prevalent throughout a large part of the country, particularly in its eastern portion. There is hardly room for doubt that sporadic cases of epidemic cerebrospinal meningitis have almost constantly occurred in our midst; often perhaps escaping recognition from the fact that it is a disease the practitioner has not generally been accustomed to encounter. It was not, however, until the early part of 1898 that these sporadic cases, occurring with increasing frequency, attained the dignity of an epi- demic. The greatest number of cases were recorded in April and May; the latter part of August and the early part of September found the city practically free from the disease. The total number of cases which occurred in this epidemic can not be positively stated, as there was no system of notification, but, approximately, the number probably approached close to two hundred during the first seven months of 1898 . In presenting this report it is not the intention of the writer to dwell to any considerable extent on the history, classification, symptomatology and treatment of the disease, as these subjects have been exhaustively treated by other writers, more particularly in the excellent monograph by Councilman, Mallory and Wright, recently published by the Massachusetts State Board of Health, but a brief synopsis of the aforementioned subjects will, we hope, be deemed admissible.

The writer wishes to express his indebtedness to Drs. Christopher and Hook of this city for histories of cases furnished by them; to Dr. D. H. Ghon, assistant pathologist to the Pathological Institute of Vienna, Austria, for valuable data, especially in regard to findings made by him in his investigation of the epidemic of cerebrospinal meningitis which raged in Trifail, Steiermark; also for the many courtesies shown him by the resident and attending staffs of the Alexian Brothers, Mercy, Michael Reese, Cook County, West Side, St. Elizabeth, Augustana, St. Joseph and Maurice Porter Memorial hospitals, Chicago, and the Daily News Sanitarium for sick babies.

\section{HISTORY.}

The first authentic description of this disease is generally accredited to Vieusseaux, a physician of Geneva, who described an epidemic in that city which presented a symptom-complex that previous to his time had not been recognized as an independent disease. In America the first cases of this disease were described by Danielson and $\mathrm{Mann}^{2}$ in 1806, in which year a number of cases had occurred in Medfield, Mass. About this time also an epidemic occurred in Southern France. In Germany the disease first made its appearance in 1822 .

That these were really the initial epidemics of a disorder which had previously not existed is extremely doubtful, especially when.the confusion existing in regard to the different fevers during the eighteenth and early part of the nineteenth centuries is taken into consideration. The almost identic phenomena to which at the present time the name of cerebrospinal meningitis is given, appear in descriptions published in the eighteenth century, under the name of cerebral typhus, jail fever, spotted fever, etc. Even as late as 1846 there was considerable doubt among physicians whether they really had to deal with an independent disease in cerebrospinal meningitis, as is shown by a paper by Rampold. ${ }^{3}$ Arnell ${ }^{4}$ described an epidemic of spotted fever, the symptoms of which were closely analogous to cerebrospinal meningitis, which existed in Orange County, N. Y., in 1808-1809. From this time until about 1825 the disease was very prevalent in the eastern part of the United States, more particularly in New England. Its spread was, however, not uniform, several towns widely separated being attacked simultaneously, while in the intervening places the disease would perhaps put in an appearance after a lapse of a few years. Very few of the larger towns in Massachusetts and Connecticut en- 